\title{
PROBABILISTIC OPTIMIZATION OF FATIGUE MAINTENANCE FOR WELDED COMPONENTS IN STEEL BRIDGES BASED ON LEFM AND LCCM
}

\author{
Yong Zeng ${ }^{1 *}$-Hongmei $\operatorname{Tan}^{2}$-Dahan Chen ${ }^{2}$
}

${ }^{1}$ State Key Laboratory Breeding Base of Mountain Bridge and Tunnel Engineering, Chongqing Jiaotong University, Chongqing, China

${ }^{2}$ Mountain Bridge and Materials Engineering Research Center of Ministry of Education, Chongqing Jiaotong University, Chongqing, 400074, China

\begin{tabular}{l}
\hline ARTICLE INFO \\
\hline Article history: \\
Received: 24.2016. \\
Received in revised form: 20.6 .2016$. \\
Accepted: 4.7 .2016$. \\
\hline Keywords: \\
LEFM \\
welded component \\
fatigue; optimization \\
interest rate \\
maintenance strategy \\
\hline
\end{tabular}

\section{Introduction}

The defects of welding toes in steel bridges often lead

\begin{abstract}
:
In this paper a probabilistic-based method for fatigue maintenance optimization of steel bridge's welded joints, combined with linear elastic fracture mechanics (LEFM), the structure reliability, and life cycle cost method(LCCM) is proposed. The probabilistic analysis method can be used with the fatigue maintenance of steel bridges. Weld cracks are classified by its size and maintenance decisions, and are made according to its size classification. Maintenance cost is divided into inspection, repair and failure costs, according to the life cycle cost method. The maintenance optimization strategy is transformed to minimize the expected lifetime total costs with the constraints of the minimum acceptable reliability index to attain the most cost-optimal inspection and repair for the balanced costs between risk and safety. An example concerning the transverse stiffeners of welded components in the main girder of suspension bridge is investigated through the research of some parameters sensitivity. Among all the parameters, the inspection cost is the most remarkable. The optimal time interval of repair will delay based on the increase of the inspection cost. The optimal time interval of repair will advance based on the increase of repair cost. A discount rate can drastically change the value of the total cost, but when the probability of failure is very small, the increase of failure cost has little effect on the optimal time interval of repair. The method presented in this paper can be conducted using the similar maintenance of steel structures.
\end{abstract}

to induction of micro fatigue cracks [1]. These defects often expand under the action of repeated loading, which easily leads to the failure of welded

\footnotetext{
${ }^{*}$ Corresponding author. Tel.: +8613883238757; fax: +86-23-62652316

E-mail address: cquczy@126.com
} 
components. The influence factors of the fatigue crack evolution include the figuration of structures, material properties, the load condition, etc. All these factors are random. Due to these random factors, the probabilistic analysis method is used to deal with the fatigue cracking problem incurring in welded components of steel bridges. The inspection and repair intervention are essential to reduce and control the risk of structural failure. When a crack is detected, a way how to evaluate the structure or component reliability becomes very important and essential. The inspection and repair are the important means of control to guarantee safety of the structure. Too much inspection and repair will increase the maintenance cost, while not enough of inspection and repair may make the reliability of the structure drop below the target value, which may make the structure unsafe. Therefore, a reasonable inspection and repair strategy should find a rational trade-off between the maintenance cost and the risk of failure. The traditional maintenance method which is based on experience, not only induces higher cost, but it also results in unnecessary maintenance. So maintenance optimization should comprehensively take into account technological, economic, and management factors. Offshore engineering structures (such as offshore platforms and ship structures) have been successfully using maintenance optimization method based on the probability in their maintenance activities [2-4]. However, there are still few published papers using maintenance methods based on the probability in civil engineering, especially with the steel bridges.

Kim and Frangopol [5,6] introduced a probabilistic method for searching the optimal inspection and/or monitoring plan for fatigue sensitive structures. Their method includes a time-based failure criterion and safety margin with the target of minimizing the total cost. The total cost includes the monitoring/inspection costs in addition to the expected failure cost. Chung et al. [7] formulated an optimization algorithm for inspection scheduling that minimizes the cost while considering the safety of the detail. The cost (in their research) included both the inspection cost and the failure cost. Their approach was used to find the optimal time interval between the inspections of different inspection methods. However, regular NDT inspections may be only practical for a limited number of bridges that are known to be highly critical. Kim and Frangopol $[8,9]$ established a procedure that can find the optimum inspection times while minimizing the expected damage detection delay. Their work was based on the fact that delayed damage detection would lead to a delayed maintenance which in turn may increase the risk of the failure for a given structure. Orcesi and Frangopol [10], based on lifetime functions, introduced a probabilistic approach for optimizing the inspections and repairs of bridges. Mohamed Soliman et al. [11] proposed a probabilistic inspection scheduling approach for fatigue sensitive steel bridges using NDI techniques. The approach is capable of handling, simultaneously, multiple critical details that exist in a bridge. The method starts by predicting the time-dependent crack growth of each detail, using a LEFM approach integrated into a Monte Carlo simulation. This process provides the time-dependent crack size, as well as the PDF of the time of failure of each considered detail.

The costs of the bridge maintenance activities are divided into inspection cost, repair cost, and failure cost. The maintenance strategy optimization method based on the probability of fatigue maintenance activities of steel bridge has been proposed in this paper.

\section{Fatigue reliability of welded steel components}

The crack evolution of welded steel components in bridges should generally include two processes: crack initiation and crack expanding. Because initial defects may exist in the components of steel bridge inevitably, the life of fatigue crack initiation is nearly zero and may be neglected. The steel component containing the initial crack $a_{0}$ only needs to be considered to have the fatigue crack expanding life. Under the repeated stress, the expanding life of the initial crack can be calculated under the Paris's Law, which was proposed by Paris and Erdogan, and is written as [12-13]:

$$
\frac{d a}{d n}=C(\Delta K)^{m}
$$

where $a$ is a size of a crack in the steel component, $\mathrm{n}$ represents stress cycle times, $m$, and $C$ are the material fatigue coefficient parameter and exponent parameter. The computation of $\Delta \mathrm{K}$ is especially complex in the common use of welded steel structures. It can be expressed in terms of crack shape and size as:

$$
\Delta K=\Delta \sigma Y(a) M_{k}(a) \sqrt{\pi a}
$$


where $\Delta K$ is the stress intensity factor amplitude, $\Delta \sigma$ is the mean stress, $Y(a)$ is the geometric correction coefficient of stress intensity factor including various factors (i.e. non-uniform stresses factor, free surface effect factor, finite width factor, and crack shape factor), $M_{k}(a)$ is the correction coefficient of stress intensity factor, which reflects the extent of $\Delta K$ when a crack tip penetrates the different structure details.

The essence of crack evolution is the joint result of the internal resistance of the component details and the external repeated load actions. Internal resistance is the inherent properties of the material, while external loads are external driving force. If Eq. (2) is substituted into Eq. (1), integrating Eq. (1), then Eq. (3) can be got.

$$
\int_{\mathrm{a}_{0}}^{\mathrm{a}_{\mathrm{t}}} \frac{\mathrm{da}}{\left[\mathrm{Y}(\mathrm{a}) \mathrm{M}_{\mathrm{k}}(\mathrm{a}) \sqrt{\pi \mathrm{a}}\right]^{\mathrm{m}}}=\mathrm{C} \Delta \sigma^{\mathrm{m}} N \mathrm{t}
$$

where $t$ is the service year of a steel component; $a_{t}$ is the crack size in time of $t ; N$ is the annual average stress cycle times.

A crack growth reaches the critical failure size $a_{f}$ (critical fatigue fracture damage size) if a size of a crack is more than $a_{f}$, then

$$
\int_{a_{0}}^{a_{f}} \frac{d a}{\left[Y(a) M_{k}(a) \sqrt{\pi a}\right]^{m}}=C \Delta \sigma^{m} \mathrm{Nt}_{\mathrm{s}}
$$

where $t_{s}$ is the service life of a steel welded component in a steel bridge. The left side of Eq. (4) denotes structure resistance, namely the time that a crack evolves from the initial crack size $a_{0}$ to critical size, $a_{f}$, which can indicate the component fatigue resistance. The right of Eq. (4) is the cumulative effect of repetitive loads at the operation time $t$. A safety margin of a steel welded component at the operation time $t$ is expressed as

$$
M(t)=\int_{\mathrm{a}_{0}}^{\mathrm{a}_{\mathrm{f}}} \frac{\mathrm{da}}{\left[\mathrm{Y}(\mathrm{a}) \mathrm{M}_{\mathrm{k}}(\mathrm{a}) \sqrt{\pi \mathrm{a}}\right]^{\mathrm{m}}}-\mathrm{C} \Delta \sigma^{\mathrm{m}} \mathrm{Nt}
$$

If $M(t)>0, a_{t} \leq a_{f}$ then, which denotes that the component is safe. If $M(t)=0$, then $a_{t}=a_{f}$, which means that the component is in a critical state. If $M(t)<0$, then $a_{t}>a_{f}$, which shows that the component has a fatigue failure.

The failure probability is [14-15]

$$
\mathrm{P}_{\mathrm{f}}=\mathrm{P}(\mathrm{M}(\mathrm{t})<0)
$$

The expression of geometry correction coefficient of stress intensity factor, $Y_{a}$, is very complex, which is always a function of a crack size. It is difficult to obtain the joint probability density function of the random variables in Eq. (5), so there is only a numerical solution of Eq. (6), in which the first order second moment method or Monte Carlo simulation method may be used. If the first order second moment method is adopted to calculate the failure probability of Eq. (6), the relationship of failure probability and fatigue reliability index is expressed as

$$
\mathrm{P}_{\mathrm{f}}=\mathrm{P}(\mathrm{M}(\mathrm{t})<0) \approx \Phi(-\beta)
$$

where, $\Phi$ is the cumulative function of standard normal distribution.

\section{Maintenance strategy optimization}

\subsection{Detection accuracy}

A crack can be found through the non-destructive inspection (NDI) method, and appropriate maintenance measures are decided to be chosen according to the NDI results. Among the available NDI techniques, an eye-naked inspection(EI), an ultrasonic inspection (UI), the liquid penetrant inspection (LPI), magnetic particle inspection (MPI), eddy current inspection (ECI), and acoustic emission inspection (AEI) are mostly used for fatigue crack detection. Each of these techniques has its advantages and disadvantages. The influence factors of crack detection accuracy are complicated and uncertain, which directly includes the precision of the NDI instrument, detection position, and personnel operating level, and so on. Therefore, a random variable, $q$, is introduced to represent the detection accuracy of NDI, $q \in[0,1], q=0$ corresponding no detection; $q=1$ corresponding to the perfect detection, and crack size is accurately measured out. Each detection method has its own precision, namely the minimum inspection crack size $a_{d}$. When the crack size is no less than $a_{d}$, the crack cannot be detected out [17-19]. Detection accuracy, $q$, of each method is different, so its detection cost also is different, correspondingly.

\subsection{The probability of maintenance strategy}

After the crack detection at the time $t_{i}$, there always 
are three possible cases: no detected crack, crack detected but not repaired, crack detected and immediately repaired. The first two cases do not change the present situation of the component. To the third case, according to the size, $a_{t_{i}}$, at the time $t_{i}$, different maintenance strategies are adopted according the detection crack size.

If $a_{0}<a_{t_{i}}<a_{1}$, conducting the maintenance strategy 1 ;

If $a_{1}<a_{t_{i}}<a_{2}$, conducting the maintenance strategy

2 ;

......

If $a_{k-1}<a_{t_{i}}<a_{k}$, conducting the maintenance strategy $k$;

......

If $a_{n_{r}-1}<a_{\mathrm{t}_{\mathrm{i}}}<a_{n_{r}}$, conducting the maintenance strategy $n_{r}$.

If $a_{1}, a_{2}, \ldots, a_{n_{r}}$ are the crack size limits of each maintenance strategy, respectively; $n_{r}$ is the total number of maintenance strategies. Generally speaking, $a_{n_{r}} \leq a_{f}$.

$\left\{H_{c d}\left(a_{t_{i}}\right) \leq 0\right\}$ is introduced to denote the event that the actual crack size is greater than $a_{t_{i}}$ at the time, $t_{i}$; $\left\{H_{c d}\left(a_{t_{i}}\right)>0\right\}$ is introduced to represent the event that the actual crack size is less than $a_{t_{i}}$ at the time, $t_{i} . H^{(k)}$ is introduced to represent the event conducting the $k$ th maintenance strategy, then we can get Eq. (8).

$$
\begin{aligned}
& H^{(k)}= \\
& \quad\left\{H_{c d}\left(a_{k-1}\right) \leq 0\right\} \cap\left\{H_{c d}\left(a_{k}\right)>0\right\}
\end{aligned}
$$

It is assumed that there is no difference between the material fatigue property before and after the maintenance, but their statistical properties of material fatigue property are independent. After the crack repair, a safety margin of component is updated by

$$
\begin{aligned}
& M^{(k)}(t)= \\
& \int_{a_{0}}^{a_{f}} \frac{d a}{\left(Y(a) \cdot M_{k}(a) \sqrt{\pi a}\right)^{m}}-C N\left(t-t_{i}\right)(\Delta \sigma)
\end{aligned}
$$

\subsection{Probability of inspection, maintenance and failure}

At the time $t_{i}$, after NDT of cracks, a probability that cracks of the component may be checked out can be expressed as

$$
P_{i}\left(t_{i}\right)=1-P_{f}\left(t_{i}\right)=1-P\left(M\left(t_{i}\right) \leq 0\right)
$$

where $P_{f}\left(t_{i}\right)$ is fatigue failure probability of component at the time $t_{i}$, seen in Eq. (6).

At the time $t_{i}$, when we take the $k$ th maintenance strategy after cracks detection, the probability $P_{r}^{(k)}\left(t_{i}\right)$ is that:

$$
P_{r}^{(k)}\left(t_{i}\right)=P\left(\left\{M\left(t_{i}\right)>0\right\} \cap H^{(k)}\right)
$$

$\Delta P_{f}\left(t_{i}, t\right)$ is introduced to represent the probability of the component failure in the time interval $\left(t_{i}, t\right]$. $\Delta P_{f}^{(k)}\left(t_{i}, t\right)$ is introduced to represent the probability of component failure in the time interval $\left(t_{i}, t\right]$, after choosing the maintenance strategy $k$ in the moment $t_{i}$. The failure probability can be calculated as

$$
\begin{aligned}
& P_{f}(t)=P(M(t) \leq 0), 0 \leq t<t_{i} \\
& P_{f}(t)=P_{f}\left(t_{i}\right)+\Delta P_{f}\left(t_{i}, t\right) \\
& =P_{f}\left(t_{i}\right)+\sum_{k=1}^{n_{r}} \Delta P_{f}^{(k)}\left(t_{i}, t\right) \\
& t_{i} \leq t<t_{s}
\end{aligned}
$$

where,

$$
\begin{aligned}
& \Delta P_{f}^{(k)}\left(t_{i}, t\right)= \\
& \sum_{k=1}^{n_{r}} P\left(\left\{M\left(t_{i}\right)>0\right\} \cap H^{(k)} \cap\left\{M^{(k)}(t) \leq 0\right\}\right)
\end{aligned}
$$

\subsection{Maintenance strategy optimization}

According to the LCCM, the total cost of bridge maintenance is divided into inspection cost, repair cost, and failure cost. The inspection cost and repair cost are the actual costs, but the failure cost belongs to a risk effect cost representing the loss caused by the fatigue failure. Maintenance optimization 
problem becomes the minimum expected maintenance total cost problem in a given period of service life $t_{s}$, and the optimization variables are: inspection time $t_{i}$, detection accuracy $q$ and maintenance strategy $k$. Maintenance total cost is composed of the following three kinds of cost. (1) inspection cost $C_{i}(q)$, which is the function to detection accuracy $q$; (2) maintenance cost $C_{r}(k)$, which is the function of maintenance strategy $k$; (3) failure $\operatorname{cost} C_{f}\left(t_{i}\right)$, which is a function of time $t_{i}$. Generally speaking, the better the detection accuracy is, the higher the inspection cost is. The better the quality of maintenance is, the greater the maintenance cost $C_{r}(k)$ is. All costs are expected, and not real. So the influence of discount rate, as well as their probability of occurrence, should be considered. The discount rate is referred to the ratio of future prospective earnings converting into the net current value. The expected inspection, repair and failure costs respectively are

$$
\begin{gathered}
C_{I}=C_{i}(q) P_{i}\left(t_{i}\right) \frac{1}{(1+r)^{t_{i}}} \\
C_{R}=\sum_{k=2}^{n_{r}} C_{r}(k) P_{r}\left(t_{i}\right) \frac{1}{(1+r)^{t_{i}}} \\
C_{F}\left(t_{i}\right)=C_{f}\left(t_{i}\right)\left(\left(P_{f}\left(t_{i}\right)-P_{f}(0)\right) \frac{1}{(1+r)^{t_{i}}}\right. \\
\left.+\left(P_{f}\left(t_{s}\right)-P_{f}\left(t_{i}\right)\right) \frac{1}{(1+r)^{t_{s}}}\right)
\end{gathered}
$$

A fatigue maintenance optimization problem becomes the minimum problem of maintenance total cost $C_{T}\left(t_{i}, q, k\right)$ in a given period of time $t_{s}$, making the fatigue reliability of structures or components higher than the minimum predefined reliability index. Namely, that is

$$
\left\{\begin{array}{l}
\min _{t_{i}, q, k} C_{T}\left(t_{i}, q, k\right)=C_{I}+C_{R}+C_{F} \\
\text { s.t. } \quad \beta\left(t_{\mathrm{i}}\right) \geq \beta_{\text {min }}
\end{array}\right.
$$

where $\beta\left(t_{i}\right)$ is the reliability index at the time $t_{i}$, $t_{i} \in\left(0, t_{s}\right] ; \beta_{\min }$ is the minimum predefined reliability index of a steel welded component.

\section{Case study}

The proposed approach is applied to an actual suspension bridge with steel box girder across over the Yangtze River in Chongqing, China. The stiffening ribs of this bridge are illustrated as an example, and its optimization analysis of maintenance strategy is performed.

Due to the influence factors, such as material production, manufacturing process and weld type, and etc., the appearance and evolution of initial cracks of welded details and the size of cracks tend to have high uncertainty. Material fatigue parameters, $\mathrm{C}$, $\mathrm{m}$, in Eq. (4) can be reached by the fatigue crack propagation tests. The stress amplitude and the stress cycle times of components related to a real bridge operation have a greater uncertainty, so they should be taken as random variables. Critical crack size, $a_{f}$, can be reached according to the normal use of the performance, and it usually is defined as a deterministic parameter. The suspension bridge's steel box girder and the details connecting cable and diagraph of girder are shown as in Fig. 1 and Fig. 2. Each parameter used is listed in Table 1.

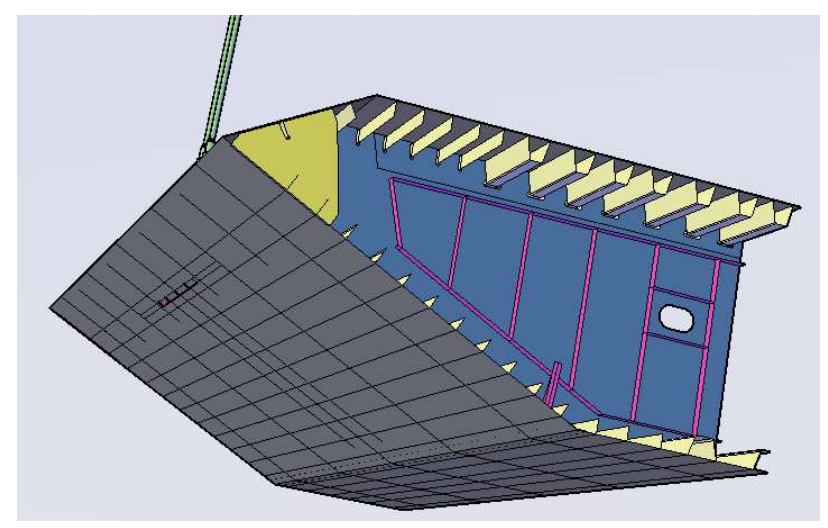

Figure 1. Steel box girder of suspension bridge

\subsection{Fatigue reliability calculation of stiffener ribs}

The reliability of stiffener ribs and failure probability calculation results are shown in Fig. 3. The predefined minimum reliability, $\beta_{\min }$, is 3.72 , corresponding to the $0.1 \%$ of the failure probability. In Fig. 3, it can be seen that when the first maintenance time $t$ is in the 19th year, the reliability index of the stiffener ribs reaches the predefined minimum value and stiffener ribs must be repaired. But this time of maintenance is not absolutely the best intervention time. 


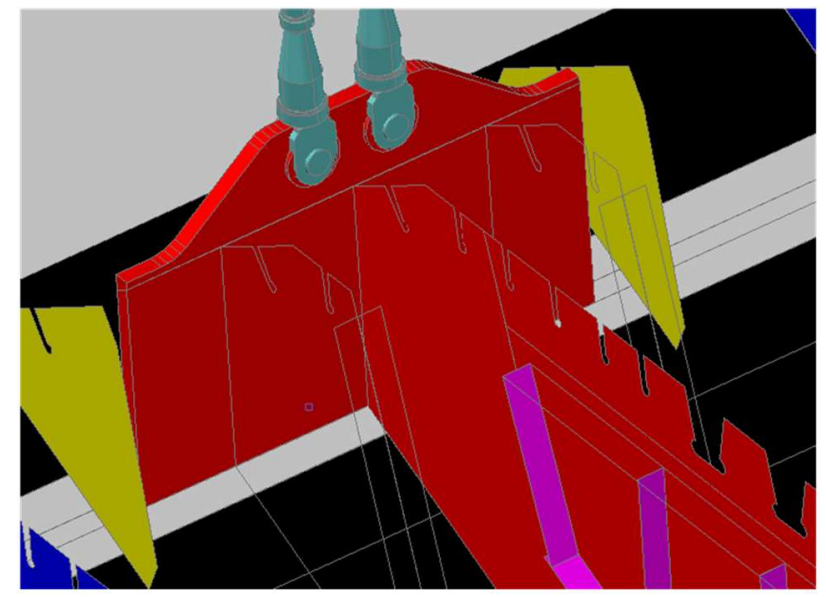

Figure 2. A detail between cable and diagraph of the girder

Table 1. Each parameter

\begin{tabular}{|c|c|c|c|c|}
\hline Statistical terms & $\begin{array}{c}\text { Distribution } \\
\text { type }\end{array}$ & $\begin{array}{c}\text { Mean } \\
\text { value }\end{array}$ & Variance & Ref. \\
\hline$a_{0}(\mathrm{~mm})$ & lognormal & 0.125 & 0.045 & {$[13]$} \\
\hline$m(\mathrm{~mm})$ & normal & 3.0 & 0.3 & {$[12]$} \\
\hline$c\left[\frac{10^{-13}}{\text { time }\left(\mathrm{N} / \mathrm{mm}^{3 / 2}\right)^{m}}\right]$ & lognormal & 2.5 & 0.923 & {$[17]$} \\
\hline$\Delta \sigma(\mathrm{MPa})$ & normal & 15.8 & 1.58 & {$[17]$} \\
\hline$N\left(10^{6}\right.$ time / year $)$ & normal & 13.87 & 1.387 & {$[7]$} \\
\hline
\end{tabular}

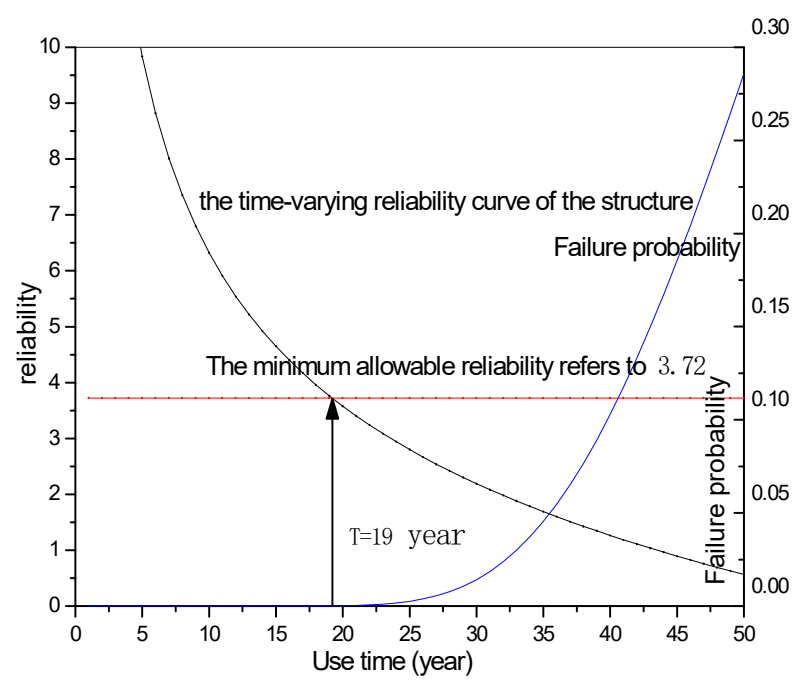

Figure 3. Reliability index and failure probability of stiffener ribs

\subsection{The optimal maintenance time}

If the costs don't change drastically, they are assumed to be constant parameters, ignoring the difference of the inspection accuracy and maintenance quality to simplify the analysis [20-22]. The inspection cost $C_{i}$, repair $\operatorname{cost} C_{\gamma}$ and failure $\operatorname{cost} C_{f}$ are equivalent to a ratio of a middle number $C^{(n)}$. $C^{(n)}$ is a parameter which is introduced. Based on the existing referred data, the values of each cost can be listed in the table 2.

Table 2. Values of optimization variables

\begin{tabular}{|c|c|c|c|}
\hline$C_{i} / C^{(n)}$ & $C_{r} / C^{(n)}$ & $C_{f} / C^{(n)}$ & Discount rate \\
\hline 1 & 20 & 1000 & $5 \%$ \\
\hline
\end{tabular}

If the values of the variables in Table 2 are substituted into Eq. (17), the expected inspection, repair and failure costs can be computed. The relationship between each cost are shown in Fig. 4. It is seen when $\mathrm{t}$ is in the $11^{\text {th }}$ year, the total cost is less, and the optimal maintenance time goes ahead in the $8^{\text {th }}$ year.

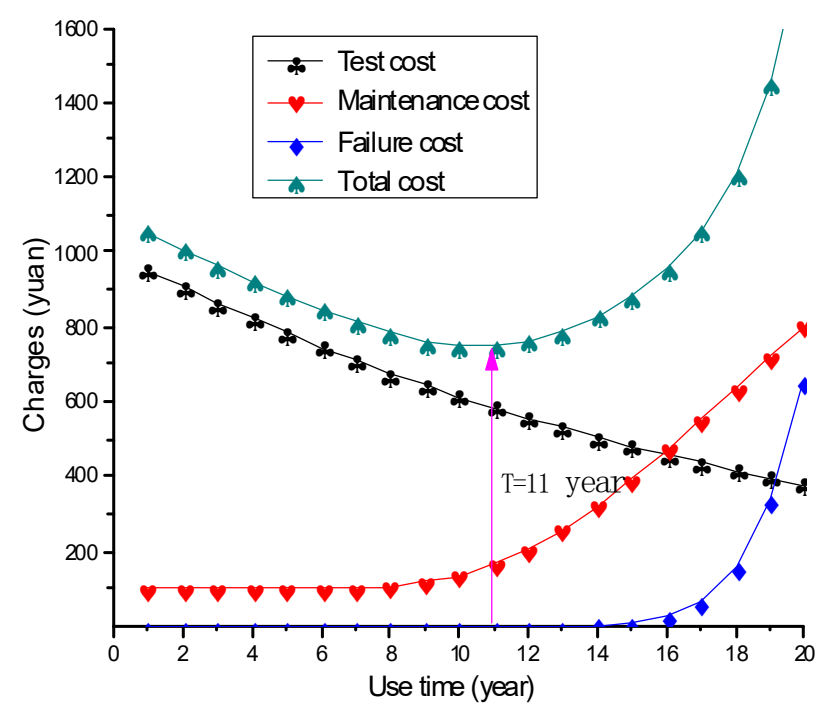

Figure 4. The diagram between expected inspection, repair and failure costs

\subsection{Parameter sensitivity analysis}

In order to investigate the importance of various parameters and the influence to Eq. (17), the sensitivity analysis of various parameters is very necessary.

(1) The influence of the test cost

If the inspection cost is $1,2,3,4,5$ and 10 times of the initial inspection cost, respectively, the changes of total cost are shown in Fig. 5. The optimal repair time delays with the increasing of inspection cost. The optimal repair time in the $11^{\text {th }}$ year with the 1 time 
initial inspection cost; but the optimal repair tim is in the 18 th with the 10 times initial inspection cost.

(2) The influence of the repair cost

If the repair cost is $1,2,3,4,5$ and 10 times of initial repair cost, respectively, the changes of the total cost are shown in Fig. 6. The optimal repair time goes ahead with increasing of repair cost. The optimal repair time is in the $11^{\text {th }}$ year with the 1 time initial repair cost; but the optimal repair time is in the $7^{\text {th }}$ year with the 10 times initial repair cost.

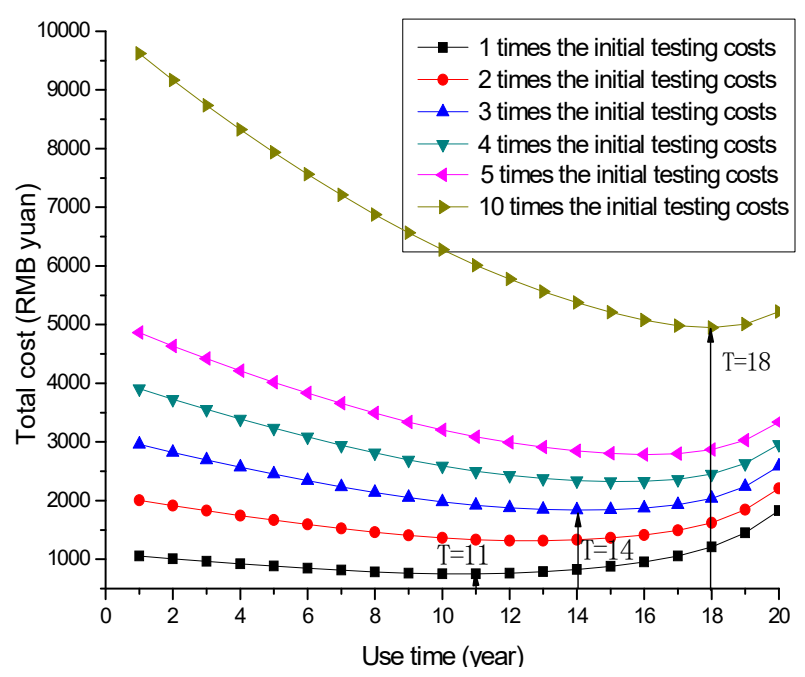

Figure 5. The relationship of total costs with respect to different test costs

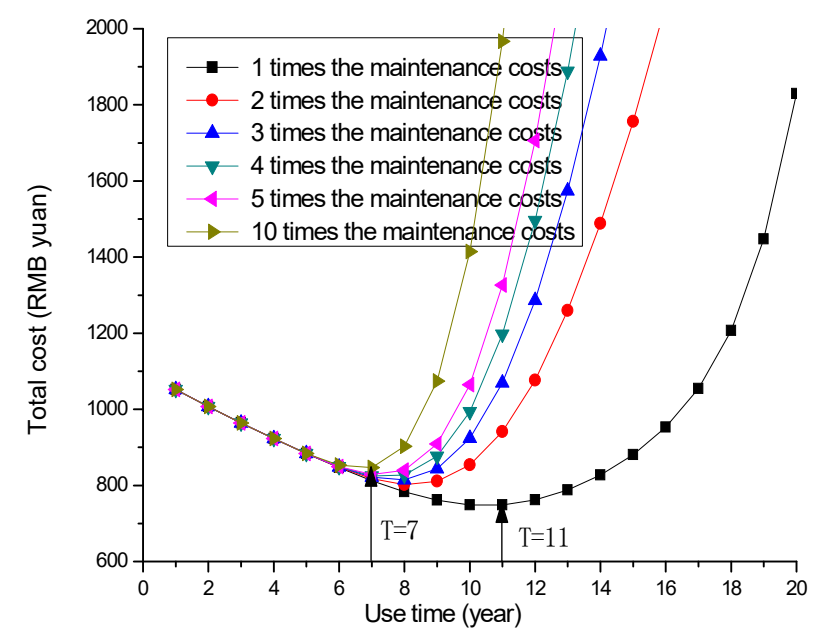

Figure 6. The relationship of total costs with respect to different repair costs

(3) The influence of failure cost

If it is $1,2,3,4,5$ and 10 times of the initial failure cost, respectively, the change of the total cost is shown in
Fig. 7. The optimal maintenance time of different failure costs are basically unchanged. The optimal repair time is in the $11^{\text {th }}$ year with the 1 time initial failure cost; but the optimal repair time is in the $10^{\text {th }}$ year with the 10 times initial failure cost. The key reason is that the failure probability of stiffener ribs is very small.

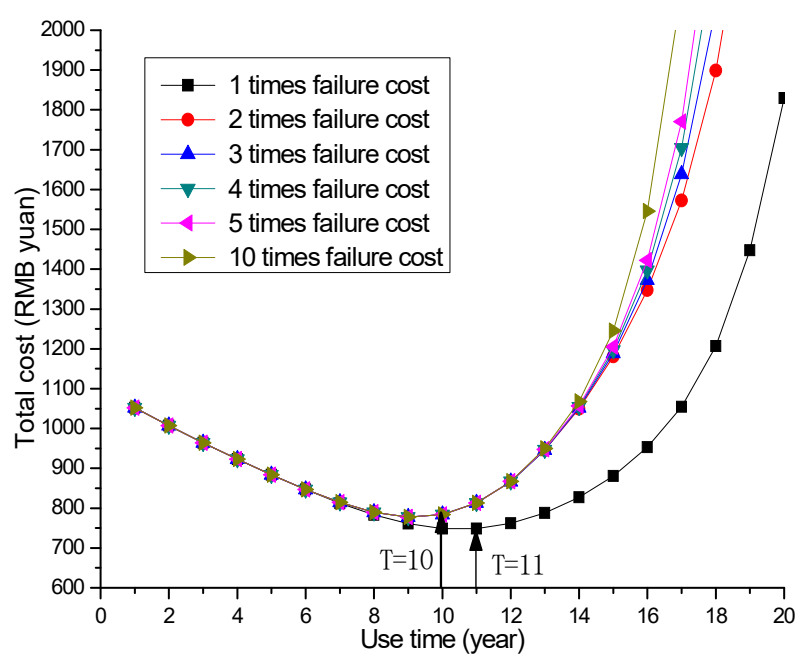

Figure 7. The relationship of total costs with respect to different failure costs.

(4) The influence of discount rate

If the discount rate is from $4 \%$ to $10 \%$, respectively, the changes of the total cost are shown in Fig. 8.

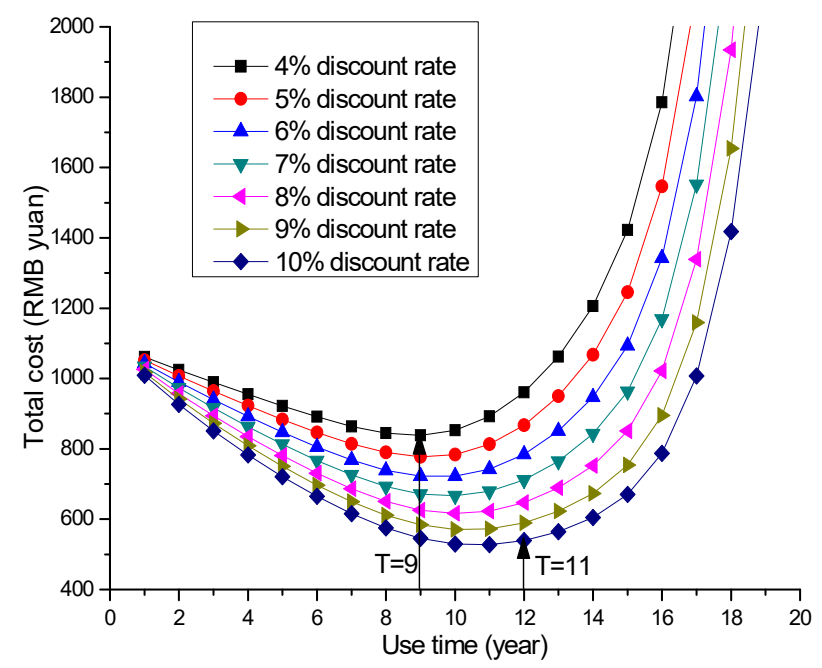

Figure 8. The relationship of total costs with respect to different discount rates

The optimal maintenance time delays with an increase in discount rate. When the discount rate is $4 \%$, the optimal repair time is in the $9^{\text {th }}$ year; when the discount rate is $5 \%$, the optimal repair time is in 
the $10^{\text {th }}$ year; and when the discount rate is $10 \%$, the optimal repair time is in the $11^{\text {th }}$ year. The discount rate has a great influence on the value of the total cost The discount rate not only obviously changes the minimum value of the total cost, but also changes the optimal repair time.

\section{Conclusion}

In this paper, a probabilistic inspection scheduling approach for fatigue sensitive detail of steel bridges using LEFM and LCCM is presented. The approach starts with predicting the time-dependent crack growth of a detail using an LEFM approach integrated into the first order second moment method or a Monte Carlo simulation. This process provides the time-dependent crack size as well as the PDF of failure time of each of the considered details. The objective of this optimization process is to minimize the total maintenance cost. The optimization process is formulated to find the optimal repair times. The following conclusions are drawn:

(1) The method minimizes the total cost for the optimization maintenance, under the condition of satisfying the minimum allowed reliability index. The total cost of maintenance is divided into inspection cost, repair cost, and failure cost. The repair strategy of cracks is adopted according to its size classification from detection result.

(2) Taking into account the fatigue maintenance of a steel bridge'sstiffener as an example, the results of the strategy optimization analysis show that the discount rate has significantly changed the total cost, but advanced the optimal repair time. The inspection cost has a large influence on the optimal repair time. When the inspection cost increases, the optimal repair time delays. When repair cost increases, the optimal repair time goes ahead. If the probability of failure is very small, the increase of the failure cost has less influence on the optimal repair time.

(3) The repair strategy optimization method, presented in this paper, is simple, practical, and applicable. It is not only capable of handling the maintenance management of similar steel structures, but it can also be used in the corrosion maintenance optimization of steel components.

\section{Acknowledgments}

This paper is partially supported by the China National Science Foundation (51478071), Construction Tech-nology Project of Ministry of
Transport (2015318814190), Scientific Projects of Chongqing Science \& Technology Commission (cstc2013jcyjA30020, cstc2015jcyjBX0022) , Scientific Project of National Engineering Research Center for Inland Waterway Regulation (SLK2013 B04) and Scientific Projects of Mountain Bridge and Tunnel Engineering State Key Laboratory Breeding (CQSLBF-Y14-3 CQSLBF-Y16-10,), and Mountain Bridge and Materials Engineering Research Center of Ministry of Education(QLZX-2012-3, QLZX-20125).

\section{Reference}

[1] Chryssanthopoulos, M. K., Righiniotis, T. D.: Fatigue reliability of welded steel structures, Journal of Constructional Steel Research, 62 (2006), 11, 1199-1209.

[2] Faber, M. H., Sorensen, J. D., Kroon, I.: Optimal Inspection Strategies for Offshore Structural Systems, Proceedings of the 11st International Conference on Offshore Mechanics and Arctic Engineering, ASME, Calgary Canada, 1989, 145-151.

[3] Madsen, H, O., Sorensen, J. D., Olesen, R.: Optimal inspection planning for fatigue damage of offshore structures, ICOSSAR'89, San Francisco, 1990, 2099-2106.

[4] Goyet, J., Maroini, A.: Optimal inspection and repair planning: an application with a sensitivity study using IMREL methodology, International Conference on Fatigue of Welded Components and Structures, Senlis, France, 1996, 149-162.

[5] Kim, S., Frangopol, D. M.:Cost-based optimum scheduling of inspection and monitoring for fatigue sensitive structures under uncertainty, Journal of Structure Engineering, 137 (2011), 11, 1319-1331.

[6] Frangopol, D. M., Lin K. Y., Estes A. C.: Lifecycle cost design of deteriorating structures, Journal of Structure Engineering, 123 (1997), 10, 1390-1401.

[7] Chung, H.-Y., Manuel, L., Frank, K. H.: Optimal inspection scheduling of steel bridges using nondestructive testing techniques, Journal of Bridge Engineering, 11 (2006), 3, 305-319.

[8] Kim, S., Frangopol, D. M.: Inspection and monitoring planning for RC structures based on minimization of expected damage detection delay, Probabilistic Engineering Mechanics, 26 (2011), 2, 308-20.

[9] Kim, S., Frangopol, D. M.: Optimum inspection planning for minimizing fatigue damage 
detection delay of ship hull structures, International Journal of Fatigue, 33 (2011), 3, 448-59.

[10] Orcesi, A. D., Frangopol, D. M.: Use of lifetime functions in the optimization of nondestructive inspection strategies for bridges, Journal of Structure Engineering, 137 (2011), 4, 531-539.

[11] Soliman, M., Frangopol, D. M, Sunyong, K.: Probabilistic optimum inspection planning of steel bridges with multiple fatigue sensitive details, Engineering Structures, 49 (2013), 3, 996-1006.

[12] Lukic. M., Cremona C.: Probabilistic assessment of welded joints versus fatigue and fracture, Structure Engineering, 72 (2001), 3, 253-264.

[13] Crémona, C., Luki, M.: Probability-based assessment and maintenance of welded joints damaged by fatigue, Nuclear Engineering and Design, 32(1998), 3, 253-266

[14] Shi, W. W.: Structure reliability analysis [M]. Beijing: People traffic press, 1990.

[15] Ren Hu, Y., Zhen Chen, B.: Marine engineering structure fatigue reliability analysis, People's transportation Press, Beijing, China, 1996.

[16] Faber, M. H., Kroon, I. B., Sørensen, J. D.: Sensitivities in structural maintenance planning. Reliability Engineering \& System Safety, 72 (1996), 3, 317-329.

[17] Chung, H.-Y.: Fatigue reliability and optimal inspection strategies for steel bridges, The University of Texas at Austin, Austin, TX, USA, 2004.

[18] Sommer, A. M., Nowak, A. S., ThoftChristensen: Probability - Based Bridge Inspection Strategy, Journal of Structure Engineering, 119 (1993), 12,3520-3536.

[19] Zhao, Z., Haldar, A.: Bridge Fatigue Damage Evaluation and Updating Using Non-destructive Inspections, Engineering Fracture Mechanics, 53 (1996), 5, 75-788.

[20] Zeng, Y.: Monitor, maintenance and management of large span suspension bridges in lifetime. Tongji University, Shanghai, China, 2009.

[21] Solaiyappan, A., Mani, K., Gopalan, V.: Cost Tolerance Prediction Models For Electrochemical Machining Of Metal Matrix Composites, Engineering Review, 35 (2015), 3, 299-307.

[22] Cazin, D., Braut, S., Žigulić, R.: Fatigue Life Analysis Of The Damaged Steam Turbine Blade, Engineering Review, 29 (2009), 2, 33-43. 